\title{
SEMENTES E SEEDING NA REDE: O METADESIGNER E AS POSSIBILIDADES DE SUBVERSÃO PARA INOVAÇÃO SOCIAL
}

\author{
Coral Michelin \\ Universidade do Vale do Rio dos Sinos (Unisinos) \\ coral@coralmichelin.com \\ Carlo Franzato \\ Universidade do Vale do Rio dos Sinos (Unisinos) \\ cfranzato@unisinos.br \\ Chiara Del Gaudio \\ Universidade do Vale do Rio dos Sinos (Unisinos) \\ chiaradg@unisinos.br
}

Resumo: O fenômeno da globalização, entre outras coisas, tornou técnicas, ferramentas e tecnologias disponíveis para indivíduos que, até recentemente, se encontravam apenas subjugados pelos interesses dos atores que dominam os fluxos financeiros e econômicos globais. Pressupõese que as mesmas tecnologias usadas por esses atores hegemônicos podem ser aproveitadas para difundir alternativas que subvertem a lógica da dominação, espalhando, pela rede de comunicação e informação mundial, sementes que carregam potenciais inovações sociais. A partir desse pensamento, o presente artigo apresenta o seeding como uma possível ação metaprojetual, no âmbito do design estratégico, para alcançar esse propósito positivamente subversivo. Antecipando um possível obstáculo, reflete acerca do papel da subjetividade como base cognitiva na qual as sementes possam ancorar, desencadeando o processo da inovação.

Palavras-chave: Metaprojeto. Rede. Seeding. Inovação Social.

\begin{abstract}
The globalization phenomenon, among other things, turned technics, tools and technologies available to individuals who, until recently, were merely subjugated by the interest of those actors whom dominate the global financial and economical fluxes. It is assumed that the same technologies used by these hegemonic actors can be harnessed to disseminate alternatives that subvert the domination logic, spreading seeds carrying potential social innovations. From this thought, the present article presents seeding as a possible metadesign action, in the strategic design domain, to reach this positively subversive purpose. Anticipating a possible obstacle, it reflects on the role of subjectivity as a cognitive basis on which the seeds can anchor, unleashing the innovation process.
\end{abstract}

Keywords: Metadesign. Network. Seeding. Social Innovation. 


\section{INTRODUÇÃO}

Três fenômenos interligados influenciam largamente nossa sociedade, moldando-a a seus contornos atuais: a globalização, as tecnologias da informação e comunicação e a organização em rede.

Segundo Milton Santos (2012, p.23), a globalização é o "processo de internacionalização do mundo capitalista" e trata da construção de um discurso único a serviço de um império do capital. Dito de outra forma, é a tentativa de hegemonizar a cultura global com base na monetarização e economização das vidas sociais e pessoais (ibid.), em favor de um império regido segundo lógicas financeiras descoladas da realidade social (TOURAINE, 2011). Alguns autores mencionam a existência de ambivalência na globalização, como aponta Morin (2013) ao dizer que ela gerou ao mesmo tempo zonas de prosperidade e zonas de miséria no mundo, no entanto Santos (2012) parece afirmar que é seu lado mais perverso o que de fato prevalece e é sentido pela maior parte da humanidade. Santos (ibid.) enumera quatro fatores que compõem o fenômeno globalizante, sendo dois de nosso particular interesse: a unicidade da técnica $^{1}$ (sistemas de ferramentas, instrumentos e tecnologias disponíveis); e a convergência dos momentos (aqui e agora em qualquer tempo/espaço). Quem são os atores desse momento convergente, que podem usufruir das tecnologias que estão disponíveis aqui e agora? Poderíamos pensar que são as pessoas no seu todo, porém vemos a história ser gravada segundo a voz daqueles poucos que comandam o discurso ideológico e são donos do tempo instantâneo e da informação. São esses atores que controlam os fluxos globais, que buscam a hegemonia do "império do dinheiro" sobre a lógica social.

A predominância dessa dimensão financeira na ordem e organização da sociedade traz como consequência a difusão e a afirmação de práticas sociais e cotidianas infiltradas por ela. Práticas que intensificam os comportamentos competitivos característicos das ações hegemônicas e chegam a promover dinâmicas socialmente e ambientalmente não sustentáveis. O processo de globalização e o enraizamento de tais práticas foi em grande parte sustentado pelo sistema de técnicas disponíveis atualmente: o fenômeno de criação de uma suposta aldeia global encontrou uma base forte para difusão nas tecnologias de informação e comunicação. Desde o final do século passado tais técnicas vêm se tornando cada vez mais disponíveis e acessíveis aos mais diversos atores, promovendo uma intensa revolução que tem remoldado as bases materiais da sociedade (CASTELLS, 2009). De fato, se na revolução tecnológica o que transforma a sociedade é a forma pela qual as tecnologias interagem com as atividades do homem, fica claro, como Castells (2009) aponta, que as tecnologias de informação e comunicação não influenciam a sociedade por uma ação externa, mas que são o mesmo tecido onde as atividades humanas são exercidas - um tecido em forma de rede.

Ao constatar a "tirania do dinheiro" e a "tirania da informação" perpetradas pelos atores hegemônicos em sua busca por controlar os fluxos globais, Santos (2012) nos apresenta uma oportunidade de ação. Se tais atores utilizam, para exercer seus domínios, das mesmas técnicas cada vez mais acessíveis aos demais indivíduos, como podemos subverter a ordem dos seus fluxos para que estes não estejam à serviço da

\footnotetext{
${ }^{1}$ Santos (2012) chama de técnicas o que aqui identificamos como englobando as tecnologias de Castells (2013) e, por isso, ambos termos são usados alternadamente.
} 
tirania, do capital, da competitividade e da desigualdade, mas sim respondendo às necessidades dos muitos atores cujas vozes não ditam as páginas da história? Quais são as estratégias possíveis para que isso aconteça?

Este artigo propõe explorar uma possível subversão das tecnologias da informação por meio do design, com suas oportunidades e desafios. Reflete acerca do papel do designer estratégico em contribuir para a oposição à hegemonia por meio da abordagem do metaprojeto e do conceito de seeding que este traz. Ou seja, coloca no âmbito do design a construção de dinâmicas sociais e ambientais mais sustentáveis e igualitárias que as atuais. O ponto de partida da reflexão atenta para a possibilidade de utilizar a rede tecnológica de informação e comunicação - usada até então para difusão e afirmação de práticas hegemônicas e excludentes - para disseminar práticas de resistência, de empoderamento social e de construção de uma nova realidade. Mas como as mesmas dinâmicas poderiam ser usadas de forma subversiva?

Diferentes autores do design estratégico têm apresentado como o design pode contribuir para promoção de práticas alternativas e mais sustentáveis usando em parte os mesmos recursos tecnológicos e organizacionais como, por exemplo, Manzini (2008 e 2015) e van Abel (2011). As práticas subversivas consideradas por estes autores pertencem ao âmbito das inovações sociais. Adotamos aqui a definição de CaulierGriece et al. (2012) para inovação social:

\begin{abstract}
"Inovações sociais são novas soluções (produtos, serviços, modelos, mercados, processos, etc.) que simultaneamente atendem uma necessidade social (mais eficazmente que soluções existentes), conduzem para novas ou aprimoradas capacidades e relações e melhoram o uso de recursos e ativos. Em outras palavras, inovações sociais são boas para a sociedade ao mesmo tempo que aperfeiçoam sua capacidade de agir" (CAULIER-GRICE et al., 2012, p.18, tradução nossa).
\end{abstract}

Na perspectiva das formas de subversão, Murray et al. (2011) explicam que a replicação é uma das formas mais comuns de crescimento das inovações sociais e, de forma semelhante, Manzini (2008) menciona franquias e formats entre as possibilidades do design para a inovação social. Estas são estratégias de difusão tradicionais, que consistem justamente em replicar um modelo de maneira a obter um novo exemplar, idêntico ao original. Estes mesmos autores, porém, sublinham a necessidade das inovações sociais se adaptarem aos diversos contextos, evoluindo em novas propostas. Seguindo essa última afirmação, desejamos aqui apresentar e discutir o seeding como forma de propagar possíveis inovações sociais adaptáveis a diferentes contextos. Este potencial será aqui discutido por meio de uma articulação entre os conceitos de rede, à luz de Capra (1996) e Castells (2009 e 2013), e de seed (semente) e seeding abordado por Giaccardi (2005), também em parceria com Fischer (2004 e 2005); esboçaremos as possibilidades de implementação do processo apresentado, suas oportunidades e limites, nos processos de inteligência coletiva de Lévy (2010 e 2011). Para tanto, o artigo está estruturado da seguinte forma: uma revisão sobre o conceito de rede e as características da sociedade em rede; a apresentação das principais características da abordagem metaprojetual e do conceito de seeding; uma reflexão sobre a relevância da dimensão contextual no processo de mudança; e, finalmente, apresentação de 
caminhos possíveis a partir da apresentação de potencialidade e obstáculos, e do papel do metadesigner neste contexto.

\section{A REDE E A SOCIEDADE EM REDE}

A compreensão da sociedade em rede, ou seja, em que a forma predominante de organização é em rede, passa por uma compreensão abrangente e integrativa justamente do conceito de rede. O pensamento sistêmico parece apresentá-lo de forma a satisfazer esse olhar, uma vez que busca compreender os fenômenos dentro de um contexto maior. "Sistema" é o todo integrado que não pode ser compreendido a partir apenas do estudo de suas partes separadas, isto é, suas propriedades essenciais surgem a partir das relações que se dão entre suas partes (CAPRA, 1996).

No âmbito do pensamento sistêmico o que importa é a qualidade das conexões estabelecidas em um sistema. Quando o foco passa das partes para as relações, percebemos que a organização do sistema segue um padrão de rede. Segundo Capra (1996), o padrão de organização de organismos vivos - e sistemas sociais aqui são considerados vivos - é então este padrão de rede, composto por inúmeras relações. Ao fim de entender o funcionamento das redes se torna relevante compreender a hierarquia da natureza: é simplesmente a ordem multinivelada pela qual a natureza opera (ibid.), sem direcionamento de fluxos por atores hegemônicos, como ocorre na hierarquia social humana. $O$ autor explica que:

\footnotetext{
"desde que os sistemas vivos, em todos os níveis, são redes, devemos visualizar a teia da vida como sistemas vivos (redes) interagindo à maneira de rede com outros sistemas (redes). [...] Em outras palavras, a teia da vida consiste em redes dentro de redes" (CAPRA, 1996, p.35).
}

Nesta visão, ir do macro ao micro significa descortinar redes, camada após camada. Em suma, redes são relações que conectam nós, quer sejam eles atores humanos, tecnológicos ou biológicos, distribuídos em espaços que vão do microscópico ao global. Essa definição abrangente se torna fundamental se quisermos entender os mecanismos de funcionamento não só da natureza, mas também da sociedade humana. Esta ultima é regida pelo mesmo princípio não hierárquico da natureza, mas segue forçosamente a lógica do império do dinheiro citado por Santos (2012), que parece dividir a rede entre poucos atores comandantes (hegemônicos) e muitos atores comandados. No âmbito social as redes constituem, por exemplo, os sistemas de comunicação e de informação, os sistemas financeiros e os logísticos.

O funcionamento e a hierarquia que caracterizam a rede do engendrar humano são explicados por Castells (2009): de acordo com o autor a nossa sociedade é organizada por fluxos, de capital, de tecnologia, de informação, fluxos de imagens, sons e símbolos, que dominam as esferas econômica, política e simbólica da vida. Tais fluxos são organizados em um espaço de fluxos que dá suporte material às práticas sociais, e que é descrito pela combinação de três camadas. A primeira delas é constituída por um circuito de impulsos eletrônicos que dão suporte material à simultaneidade. Trata-se da infraestrutura tecnológica. Importante observar que, de acordo com Santos (2012), as tecnologias (ou "técnicas", nos termos do autor) normalmente avançam por meio dos atores mais influentes na sociedade (como aqueles que controlam os meios de comunicação), mas recentemente se tornam cada vez mais acessíveis aos demais atores sociais. A segunda camada é feita pelos nós deste espaço, pelos centros de funções 
estratégicas e centros de comunicação. Isso significa que a rede também é composta por "lugares específicos com características sociais, culturais, físicas e funcionais bem definidas" (CASTELLS, 2009, p.502), pontos que conectam localidades à rede geral e que podem ter maior ou menor relevância de acordo com o papel que desempenham. 0 terceiro nível desse espaço de fluxos diz respeito justamente às hierarquias dominantes, ao redor das quais o espaço de fluxos se ordena. De fato as elites detém o poder de organização dos fluxos e de desestruturação dos demais grupos sociais em torno dos seus interesses.

É importante, porém, observar que esta última lógica de dominação tem sofrido mudanças ao longo do tempo. O próprio Castells identifica, em Redes de indignação $e$ esperança (2013), alguns movimentos que partem dos grupos sociais menos favorecidos e são impulsionados pela disponibilidade crescente das técnicas de comunicação e informação. Ou seja, o mesmo acesso a essas tecnologias da informação e comunicação traz consigo a possibilidade de organizar fluxos que se opõem aos dominantes. Diversas plataformas, mas principalmente a rede da internet, possibilitam que novas vozes despontem e assumam o papel de liderança em movimentos sociais e práticas que desafiam as hegemonias estabelecidas pela elite (CASTELLS, 2013). Os movimentos sociais observados por pelo autor - a revolução egípcia em 2011, as indignadas espanholas, o movimento occupy, entre outros - estão mostrando que os mesmos suportes materiais do espaço de fluxos podem ser usados para quebrar a hierarquia humana, aproximando os sistemas sociais da lógica da hierarquia da natureza (CAPRA, 1996). Todavia, tais tecnologias por si só não são suficientes, uma vez que romper com dinâmicas hegemônicas e promover a difusão e afirmação de novas práticas sustentáveis requer estratégias de longo prazo, muita insistência e perseverança. Portanto, se torna necessário entender como desenvolver estas estratégias. Como antecipado na introdução, acreditamos que o design estratégico, em especial quando encarnado na persona do metadesigner, possa desempenhar um papel fundamental para que isso aconteça, contribuindo para uma "des-hierarquização" e "deshegemonização" da rede social. No escopo das estratégias que ele poderia desenvolver para subsidiar este propósito positivamente subversivo está o seeding, definido a seguir e que aqui implica na infiltração do sistema com "sementes de esperança": ideias, códigos, conhecimentos que propõem novos formatos, métodos e conexões, e esperam o momento certo, o contexto propício, para vir à tona. De fato, está na bagagem do metadesigner a habilidade técnica projetual, o domínio de ferramentas estratégicas e o conhecimento para projetar uma ação de seeding (FISCHER; OSTWALD, 2002). Esta capacidade, junto com as características e o potencial destas sementes, serão aprofundadas na seção seguinte.

\section{O METAPROJETO E O SEEDING}

Metaprojeto (ou metadesign - usados aqui como sinônimos) é uma abordagem metodológica cuja definição é ainda ambígua, com diferentes posicionamentos dependendo dos autores a quem se recorre. Consideramos aqui as visões de Franzato (2014), Fischer e Giaccardi (FISCHER; GIACCARDI, 2004 e 2005; GIACCARDI, 2003 e 2005).

Franzato apresenta o princípio de deslocamento característico dessa abordagem, que consiste na "possibilidade de desenvolver processos projetuais sobre o design, 
resultando em sistemas, ambientes, plataformas ou cenários que habilitam o mesmo design" (FRANZATO, 2014, p.1188). O metaprojeto aparece então como uma reflexão constante sobre o próprio processo de design. Usando a perspectiva de Van Onck (1965), o autor explica que o metadesign define as regras do processo de design, uma vez que ocorre em um nível diferente, deslocado deste último. Além disso, sua ação traz como resultado sistemas, plataformas ou ambientes onde designers e não-designers são capacitados a agir projetualmente.

Fischer e Giaccardi (2004, 2005), de forma semelhante, enxergam metaprojeto como uma metodologia de design caracterizada por atividades e processos direcionados para a criação de ambientes ou artefatos - infraestruturas sócio-técnicas - que evoluem com o tempo e possibilitam a ação de designers e codesigners dos próprios ambientes e artefatos criados. Giaccardi (2005) apresenta o designer como criador de uma ideia executável (um código generativo), isto é, como criador não de artefatos finalizados, mas sim de processos que, quando iniciados, se transformam em artefatos evolutivos. Aqui está o fio condutor do metaprojeto para o seeding. Tais códigos generativos podem ser compreendidos como "sementes" que germinarão artefatos "finais" (o "final" sendo sempre uma evolução constante); embriões que dão origem a sistemas. Dessa maneira, o metadesigner não projeta o artefato final, mas o embrião para o projeto de artefatos finais. Fischer (FISCHER; OSTWALD, 2002; FISCHER; GIACCARDI, 2004) afirma que uma semente é uma formação inicial de conhecimento - que pode se apresentar na forma de um código de programação, por exemplo - projetada para evoluir ao longo do tempo, como um sistema em constante adaptação ao seu contexto. Para este autor, tal evolução só é possível de acontecer através da ação direta dos codesigners do sistema, ou seja, daqueles que farão uso do artefato lançado em um contexto, entendendo que os designers da semente inicial não estão necessariamente presentes no desenvolvimento e evolução do sistema ao longo de todo seu tempo de uso.

Para que exista a evolução, um sistema precisa de abertura. De forma muito sucinta, podemos entender um sistema aberto como aquele que se encontra constantemente em estado de equilíbrio dinâmico, ou seja, regulando fluxos de entrada e saída de matéria, energia ou informação que mantêm a sua vitalidade; sistemas abertos regulam sua abertura pelo seu fechamento, se adaptando constantemente ao meio onde se encontram (CAPRA, 1996; MORIN, 2005). De fato, o sistema a ser originado a partir da semeadura precisa se adaptar constantemente às mudanças do seu contexto, imprevisíveis no momento de sua concepção. Para fazê-lo precisa do intermédio da ação dos atores nele diretamente envolvidos. Planejar um sistema completo do começo ao fim significaria, ao contrário, isolá-lo, subtrair do horizonte as conexões que poderiam acontecer no seu desenvolvimento. Seria como projetar uma semente estéril.

O design do seeding fica a cargo dos metadesigners, os profissionais que, no momento do projeto, não criam soluções fechadas, mas sim ambientes abertos que podem ser modificados através de processos colaborativos no tempo de seu uso (GIACCARDI, 2003). Fischer e Ostwald (2002) usam o termo informed participation para definir uma forma de design colaborativo que busca solução para os problemas mais complexos de nossa sociedade mutante: desafios que combinam questões sociais e tecnológicas e exigem a constante atualização dos conhecimentos necessários para enfrentá-los. 
Observamos assim que a colaboração está na base tanto do codesign, como da visão sistêmica, pois as propriedades que definem um sistema surgem a partir das relações entre suas partes constituintes - são propriedades do todo que desaparecem quando seus componentes são isolados ou dissecados física ou teoricamente (CAPRA, 1996). De acordo com isso e com uma abordagem de informed participation, se as relações definem o sistema e suas trocas com o contexto no qual está inserido, o design do seeding precisa fomentar as interações que se darão após seu "germinar", ou seja, sua catalisação em um determinado contexto. Em resumo, sementes são embriões que carregam códigos parciais para o desenvolvimento de sistemas abertos; que precisam evoluir criando relações entre seus atores e seu contexto fomentando, dessa forma, a colaboração; e que, no âmbito da sociedade, podem carregar o potencial para inovações sociais subversivas com relação às dinâmicas hegemônicas existentes. O que poderia ser uma semente para essa sociedade, contexto deste artigo?

Dentro da esfera da inovação social, se destacam as organizações colaborativas (OCs) apresentadas inicialmente por Manzini (2008). OCs são comunidades criativas maduras, compostas por pessoas que atuam em escala local e, rearticulando os recursos já existentes aos quais têm acesso, propõem inovações sociais que funcionam como pequenas rupturas nos macro-sistemas vigentes (ibid.) -aqueles cujos fluxos são comandados pelos atores hegemônicos, dessa forma contendo em si, a priori, um potencial subversivo. OCs são sistemas abertos por natureza (BASSO et al., 2016) que, por sua vez, dependem de processos colaborativos para evolução e adaptação constante. Esta é uma das propostas que mais se aproxima de um seeding para o âmbito social. Com efeito as OCs têm potencial para propor soluções para os mais variados problemas sociais, de mobilidade urbana à alimentação saudável. Para semearem, porém, elas precisariam ser projetadas de forma a conter diretrizes propiciando sua evolução, isto é, mecanismos de fomento à interação e à colaboração de seus codesigners.

O seeding das OCs se ocuparia então de difundir tais organizações de um contexto para outros através de redes (tecnológicas ou de projeto); ideias que seriam colocadas em prática por meio de processos de projeto colaborativos, igualmente em rede, sendo reinterpretadas, transformadas e renovadas para então serem introjetadas e implementadas em diversos contextos - como um processo rizomático (em alusão à Deleuze e Guattari) de proliferação e adaptação. E assim sucessivas vezes, em uma difusão contínua. Podemos tentar aprofundar esse processo, encarando o objetivo positivamente subversivo desejado, para entender como uma semente poderá se espalhar através dos mesmos recursos que os fluxos hegemônicos usam, as tecnologias de informação e comunicação.

\section{CONTEXTO DE MUDANÇA}

$\mathrm{Na}$ seção anterior abordamos a possibilidade de metaprojetar as soluções inovadoras de organizações colaborativas na forma de sementes. No contexto da rede social e da subversão de um paradigma insustentável que estamos considerando, a semente é, antes de mais nada, uma possibilidade de ação: uma sugestão de solução que pode ser co-criada para enfrentar uma determinada questão.

Esse embrião, após ser lançado no espaço de fluxos da sociedade, precisará encontrar um contexto favorável para ancorar e então desenvolver-se. Em uma rede 
social, não há como se escapar da dimensão da subjetividade humana (GUATTARI, 2012): uma semente, para ancorar e germinar, precisará dialogar com o universo subjetivo presente na rede onde tiver sido lançada. Castells (2013) mostra que a mensagem constrói o meio: ela se espalha quando reflete a experiência pessoal daqueles que estão presentes, ou seja, quando representa um universo familiar. A semente apresenta-se, dessa forma, como um universo incorporal de Guattari (2012) uma exterioridade que, para germinar, precisa incorporar-se. Sua ancoragem se dá por meio de um processo de subjetivação, de tomar para si a ideia, o conhecimento, uma "nova" verdade ou um valor redescoberto nela contida. A subjetividade, a maneira como o sujeito se relaciona com o mundo, determina, pelo menos em certo grau, as suas escolhas, suas prioridades e sua maneira de enxergar a realidade. A semente somente será sistema se os atores daquele espaço, daquela rede, tomarem para si a tarefa de enfrentar o problema proposto.

Um contexto adequado para semear apresenta também uma base cognitiva por meio da qual o sistema pode evoluir, uma vez que esteja ancorada a semente. Lévy (2011) propõe um conceito para inteligência coletiva que pode servir como essa fundação cognitiva, e diz que ela é composta pelo entrecruzamento dos saberes, das capacidades e das diferenças, valorizadas, coordenadas e mobilizadas, constantemente em negociação com o contexto dinâmico. Dessarte, ela representa a confluência das subjetividades que trabalham de forma colaborativa para um fim acordado - mesmo que este fim seja, em realidade, um processo: de crescimento, de aprendizado ou de experimentação, por exemplo. Trata-se de enxergar a inteligência como uma rede organizada para a co-criação. A rede carrega a potencialidade de toda inteligência global que, uma vez articulada, propõe soluções para os inúmeros problemas enfrentados atualmente. Qual seria o resultado de centenas de sementes jogadas nesta rede global coordenada, colaborativa e motivada para quebrar suas próprias amarras?

O protagonismo no novo espaço de fluxos é desempenhado pelo sujeito que, ele próprio, opera como uma rede, como um sistema aberto aos universos incorporais que trazem novas experiências, visões de mundo e possibilidades de interpretação da realidade. Um sujeito que atua proativamente na evolução do embrião, que toma para si o problema e o desafio de solucioná-lo colaborando com a rede da inteligência coletiva. Resta agora projetar a semente.

\section{DISCUSSÃO E CONSIDERAÇÕES FINAIS}

Em um contexto no qual as diferenças, as crises e as desigualdades parecem apenas aumentar, se faz necessário o debate, mesmo que na forma de relações teóricas, acerca das possibilidades para a construção de uma nova realidade. A partir do entendimento que a vida em si é uma sucessão de redes (CAPRA, 1996), emergiu uma oportunidade para ação: se a vida opera de acordo com a lógica das redes, então é possível usar seus fluxos para promover rupturas no sistema de dominação vigente.

Nas seções anteriores foi apresentado o conceito de semente e o método do seeding (FISCHER; OSTWALD, 2002; FISCHER; GIACCARDI, 2004 e 2005). Eles têm potencial para desencadear ações sociais. Sementes na rede podem ser agentes de mudança, atores para a ruptura da hegemonia dominante. Porém isso pode acontecer somente se elas refletirem os valores, as crenças, o universo dos seus possíveis contextos. Para que o embrião se desenvolva em sistema aberto, é necessária sua 
ancoragem, garantida mediante processos de subjetivação (GUATTARI, 2012). Com efeito, as sementes que incentivam a ação social e empoderam os atores "secundários" que não dominam os fluxos globais, se espalham como potencialidades a espera de contextos favoráveis para germinar. Ao considerar as OCs anteriormente apresentadas, é possível exemplificar este conceito da seguinte maneira: uma semente pode conter as informações iniciais para que se constitua uma organização colaborativa destinada a, entre as diferentes possibilidades, solucionar o problema da desvalorização de agricultores locais, frente à concorrência desleal com produtos industrializados. Essa semente pode ser jogada na rede, mas se não houver a menor consciência acerca da importância da alimentação saudável, da sustentabilidade da produção local ou do fomento à economia regional, ou seja, se esse for um universo completamente externo aos sujeitos de determinada localidade, naquele contexto ela dificilmente conseguirá ancorar. Possivelmente haveria a necessidade de transformar o externo em incorporal.

Embora a subjetividade possa limitar o conceito do seeding e da semente, ela também traz para o design uma grande oportunidade de inovação e subversão. Como vimos, tanto a semente como sua inovação imanente evoluem e se adaptam aos diferentes contextos, podendo ser interpretadas, transformadas e usadas das mais diversas formas com os mais variados propósitos.

A partir da apresentação de obstáculos e potencialidades é possível apontar três caminhos para estudos futuros. O primeiro diz respeito aos universos incorporais e aos processos de produção de subjetividade: como o metadesigner pode preparar um espaço para que a semente lançada na rede tenha receptividade, se é que isso é possível ou preciso? Em segundo lugar, é necessário descrever em detalhe o papel do metadesigner no projeto do seeding e do designer estratégico na evolução e manutenção do sistema aberto por ele gerado. Por ultimo, sugere-se que, na alçada do metaprojeto, sejam exploradas formas de projetar uma semente factível para atuar efetivamente nessa ação social, partindo de pesquisas já desenvolvidas no âmbito do seeding, como, por exemplo, o modelo SER (seeding, evolutionary growth, reseeding) proposto por Fischer (2002). O aprofundamento destas três questões permitirá que a proposta apresentada se torne realmente uma possibilidade de contribuição do metadesign na construção de uma realidade mais igualitária e sustentável que a atual.

Na superfície mais externa das possibilidades, podemos pensar que talvez, mais do que desencadear propostas concretas de ações, a semente, uma vez jogada na rede do contexto global atual, poderá suscitar o debate, o questionamento e a reflexão acerca do momento presente e dos caminhos que nos levam para o futuro, quiçá para construir uma sociedade com a hierarquia da natureza.

\section{REFERÊNCIAS}

BASSO, C. M.; FRANZATO, C.; FREIRE, K.; BORBA, G. S. Organizações colaborativas como sistemas abertos: Contribuiç̧̃es do metaprojeto para fomentar ações de inovação social. In: Anais do 5o Simpósio Brasileiro de Design Sustentável [Blucher Design Proceedings, v.2, n.5]. São Paulo: Blucher, p. 319-330, 2016.

CAPRA, F. A teia da vida: Uma compreensão científica dos sistemas vivos. São Paulo: Editora Cultrix, 1996.

CAULIER-GRICE, J., DAVIES, A., PATRICK, R., NORMAN, W. Defining Social Innovation Part 1. A deliverable of the Project "The theoretical, empirical and policy foundations for 
building social innovation in Europe" (TEPSIE), European Commission - 7th Framework Programme, Brussels: European Commission, DG Research. 2012.

CASTELLS, M. A sociedade em rede. São Paulo: Paz e Terra, 2009.

CASTELLS, M. Redes de indignação e esperança: Movimentos sociais na era da internet. Rio de Janeiro: Jorge Zahar Editor, 2013.

DELEUZE, G, GUATTARI, F. Mil Platôs: Capitalismo e esquizofrenia 2. Vol.1. Rio de Janeiro: Editora 34, 2011.

FISCHER, G; GIACCARDI, E. Meta-Design: A Framework for the Future of End-User Development. In: LIEBERMAN, H., PATERNÒ, F., WULF, V. (Org.). End User

Development: Empowering People to Flexibly Employ Advanced Information and Communication Technology. Dordrecht: Kluwer Academic Publishers, 2004.

FISCHER, G.; GIACCARDI, E. Creativity and Evolution: A Metadesign Perspective. 2005.

FISCHER, G.; OSTWALD, J. Seeding, Evolutionary Growth, and Reseeding: Enriching Participatory Design with Informed Participation. In: Participatory Design Conference (PDC'02), 2002. Sweeden, Malmö University. p. 135-143.

FRANZATO, C. O princípio de deslocamento na base do metadesign. In: 110 Congresso Brasileiro de Pesquisa e Desenvolvimento em Design, 2014, Gramado. São Paulo: Editora Edgard Blücher, 2014, p. 1187-1196.

GIACCARDI, E. Principles of Metadesign: Processes and Levels of Co-Creation in the New Design Space. 437 f. Tese (Doctor of Philosophy) - University of Plymouth, UK. 2003.

GIACCARDI, E. Metadesign as an Emergent Design Culture. Leonardo, v. 38, n. 4, 2005, p.342-349.

GUATTARI, F. Heterogênese. In: Caosmose: um novo paradigma estético. Rio de Janeiro: Editora 34, 2012. Págs.11-90

LÉVY, P. As tecnologias da inteligência: O futuro do pensamento na era da informática. Rio de Janeiro: Editora 34, 2010.

LÉVY, P. A inteligência coletiva: para uma antropologia do ciberespaço. São Paulo: Edições Loyola, 2011.

MORIN, E. Entender o mundo que nos espera. In MORIN, E. e VIVERET, P. Como viver em tempos de crise? Rio de Janeiro: Bertrand Brasil, pp. 7-27, 2013.

MORIN, E. Introdução ao Pensamento Complexo. Porto Alegre: Editora Sulina, 2005.

MURRAY, R., CAULIER-GRICE, J., MULGAN, G. The Open Book of Social Innovation. Great Britain: NESTA \& The Young Foundation, 2010.

SANTOS, M. Por uma outra globalização: do pensamento único à consciência universal. Rio de Janeiro: Record, 2012.

TOURAINE, A. Após a crise: a decomposição da vida social e o surgimento de atores não sociais. Petrópolis: Vozes, 2011. 